\title{
Assessing the Influence of Project Manager's cultural Intelligence (CQ) on Project team dynamics. $A$ case of China-Kenya projects
}

\author{
Ngari, Peter Gitonga \\ International Business School \\ Yunnan University of Finance and Economics \\ Kunming, Yunnan, P.R. China, \\ cephasngare@yahoo.com
}

\author{
Ying Zhang* \\ International Business School \\ Yunnan University of Finance and Economics \\ Kunming, Yunnan, P.R. China, \\ angie17@qq.com
}

\begin{abstract}
Globalization and international activities of organizations have increased the cross-cultural interaction and business links, which in turn have resulted in the need for knowledge and competence about different culture in a project team. Within such team dynamics, the success of the project managers who are in charge of cross-cultural teams projects activities depends on their Cultural intelligence. Recent studies reveal that project managers' Cultural intelligence helps him or her to cope with multi-cultural situations, to perform in culturally diverse work teams, facilitate effective cross-cultural adjustment to manage culture shock, decision making and influence project team dynamics.
\end{abstract}

This study particularly investigates the role of project manager's Cultural intelligence in influencing team dynamics and further identifies the needs for future research regarding this research direction in Kenya and other parts of the world. This study also explores the role of various dimensions of cultural intelligence in influencing project team dynamics, while considering others factors that influence team dynamics available in literature such as age, gender, previous experience and level of education as control variables.

Keywords-Cultural intelligence, Project team dynamics, China-Kenya projects

\section{INTRODUCTION}

It has been observed that in the current business environment, levels of uncertainty and complexity have increased due to the rapid development of information technology and the expansion of international business. As a result, many organizations have applied a team-based work style, the team-based organization [1], the project-based organization[2] and the multi-team system [3].

According to Wellner (2000) the term diversity stand for both individual's differences and similarities that exist among people, it includes characteristics such as age, gender, race, nationality, ethnicity and cultural diversity[4]. The former (cultural diversity) is a broader concept than the national diversity because it includes global diversity which is the diversity that is found in different nations whereas the latter refers to diversity within the nation or country [5].
The term teaming has been defined as dynamic grouping, which has the flexibility to change as the work progresses, and which requires more than traditional project management to bridge different national, traditional, occupational and organizational cultures occurring in a dynamic environment [6]. In this regard, different organizations have used teambased work styles by using multiple teams or project teams to accomplish their tasks [7-8]. To deal with complex international business problems, multicultural workgroups have been emphasized by many researchers [9-11].

China-Kenya projects for the purpose of this study refer to projects being implemented by Chinese experts within the boundaries of Kenya. It is approximated that about 100 Chinese companies have currently been contracted to work on various projects in energy, roads, water, housing and transport in Kenya. Chinese government has agreed to invest in various infrastructural projects ranging from railway, conference facilities, industrial parks in Kenya for sustainable development [12]. It is important to note that Kenya Vision 2030 envisages a country with integrated and firmly interconnected transport infrastructure consisting roads, railways, airports, seaports and waterways.

In this regard, it is estimated that over 20,000 Chinese expatriates have entered the Kenyan market and are engaged in various aspects of economic development in the real estate development, infrastructure, science and the engineering sectors [13].The major companies involved in the engineering works include China $\mathrm{Wu} \mathrm{Yi}$, Synohydro Corporation, Shengli Engineering Construction Group and China Road \& Bridges Corporation a subsidiary of China Communications Construction Company Ltd (CCCC, alongside other Chinese engineering companies.

During the construction of these projects, the project teams do face issues of cultural diversity from the team members involved who are drawn from both Kenyans and Chinese nationalities. It is important to note that international assignments can be greatly challenging in the current global business environment and have become an increasingly important subject for researchers and international human resource practitioners. Baruch and Qin (2010) argue that 
expatriates should have a high degree of cultural awareness and should try to become familiar with the behavior and norms of the population of the host country which includes cultural intelligence and cultural adjustment, and which will lead to effective interaction with people, especially when working as a team from different cultural backgrounds [14].

It has been suggested that culturally intelligent people are able to interact effectively with individuals from different culture especially in a project team. They can detect, assimilate reason and act on cultural cues appropriately in situations characterized by cultural diversity. This helps individuals or managers to become more effective in decision making, communicating and negotiating across the cultures. Poor cultural intelligence leads to stereotyping, unnecessary conflicts, cultural shock, stress and unhealthy relationships. It would be essential for individuals who are working with people from other cultures, especially in the project team to be culturally sensitive when handling each other. That is why organizations see cultural intelligent managers as a source of competitive advantage and strategy.

Although Jeevan ( 2015) argues that cultural intelligence is a new and growing concept with limited research on this subject and that it is based on Sternberg and Detterman's (1986) framework of the multiple foci of intelligence [15]. A number of research [16-17] have been conducted on the concept of the cultural intelligence.

However, it has been noted that majority of these researchers concentrated on the influence of $\mathrm{CQ}$ on expatriate's adjustment but minimum research has been done on the relationship between CQ and team dynamics. Green (2010) investigated the interrelationship between interpersonal skills, team dynamics, emotional intelligence and project outcomes, in a case study within the U.S. Army's Integrated Materiel Management Center (IMMC). But in the literature, there is Limited research on the relationship between cultural intelligence and variables such as interpersonal skills, project team dynamics and its effect on project outcomes [18].

Earley and Gardner (2005) conducted a study on the relationship between internal team dynamics and cultural Intelligence in multinational teams; however they did not cover external team dynamics. That is how the organizations build project teams and maintains them to realize positive project outcomes. According to Earley and Gardner, managers with a higher CQ are able to interact freely with workers from different cultural background and hence influence internal team dynamics positively [19].

All the studies given above were conducted on the relationship between $\mathrm{CQ}$ and such variables as cultural adjustment, task performance and internal team dynamics but no study on CQ and team dynamics as a whole. Therefore this study seek to analyze the impact of project managers' CQ on the project team dynamics using Chinese construction projects in Kenya as a case study. Most of the studies have been conducted on the impact of expatriates' level of cultural intelligence on cross cultural adjustment and none have studied cultural intelligence within a country like Kenya, which has diverse cultures just like China or any other country. Again all these researchers focus on the impact of cultural intelligence on expatriates adjustment but there is limited research done on the influence of cultural intelligence among supervisors or managers on project team dynamics.

Although a study conducted by Earley and Gardner (2005) exists in literature, it examines the relationship between internal team dynamic and cultural Intelligence among some multinational teams, but the element of external team dynamics was overlooked in this study. This forms another literature gap for this study to explore the influence of CQ on both internal and external team dynamics. External team dynamics is key and involves how the organization builds project teams and maintains them to realize positive project outcomes.

There is need to further explore the scope of CQ and its influence on team dynamics especially based on this case study, for the Kenya native companies have faced among other challenges the problem of managing team dynamics within the project teams for many years [20].

Considering such engineering projects in Kenya, a daily interaction of the locals and Chinese expatriates is inevitable, as the Chinese expatriates are expected to mentor their Kenyan counterparts in the process. In this regard, both managers or workers with a higher cultural intelligence, either the locals and the Chinese expatriates become a necessary requirement to form successful project teams and ensure project success. It is observed that, lack of expatriate quick adjustment to the local culture and environment may results to disastrous results such as delays, cost overrun in such projects, misunderstanding, misinterpretation, frustrations, conflicts and damaging relationship [21].

Today's projects are far more varied and complex and they require a far more Sophisticated system of project management that should address both processes and relationships between and within a project team [22]. A research study concluded that, age group is significant in predicting team dynamics. However, no other variable was found to be significant in predicting team dynamics, like interpersonal skills, or emotional intelligence [23]. In this study however, age is considered as a control variable predicting project team dynamics but much emphasis is on the role of CQ in predicting team dynamics.

The researcher focus on project team dynamics as the dependent variables while cultural intelligence will be considered as the independent variable, other control variables may include, job position, gender, age, education and workers' experience.

Hofstede's study of 160,000 IBM Corporation employees working in 60 different countries represents one of the most comprehensive pieces of research in the field of crosscultural dimensions of behavior. Hofstede identified four different dimensions one individualism/collectivism, the degree to which individuals are integrated into groups, two power distance, acceptance or rejection of unequal distribution of power, three uncertainty avoidance index, which is tolerance for uncertainty and ambiguity, finally 
masculinity/femininity unequal or equal distribution of roles between the gender [24].

Hofstede further shows that the national culture indexes are different in different countries; typical example is the comparison of Kenya and China. For example, China has a power distance index of 80 while that of Kenya is 64 . While China advocate for collectivism, Kenya was traditionally a collective society but with time turning to advocate more of individualism due to the influence from the west. The two countries have an index of 20 and 27 respectively [25]. This phenomenon has a direct effect on project team dynamics.

According to Sanchez et al ( 2000 ) [26], the inability to learn new behaviors and respond appropriately during interpersonal interactions, raise the likelihood that expatriates will reject the host culture, develop a divisive, "us versus them" mindset (pg6). In this regard, managing such projects which is composed of a cross cultural project team will demand managers and team players with a higher CQ otherwise there will be divisions always which work against the project success.

The findings in this study can be used to address potential changes for both project managers and leaders in terms of developing and improving their cultural intelligence profiles.

\section{REVIEW OF LITERATURE}

\section{A. Cultural intelligence (CQ)}

There have been several different definitions of CQ offered over the last few years. These definitions primarily differ in the number and type of factors that constitute CQ as noted by [27]. Firstly, Ang and Earley (2003) [28] introduced the concept of cultural intelligence as referring to an individual's capability to function effectively in situations characterized by cultural diversity. Those workers with higher CQ have the ability to encounter confusing situations, think deeply about what is happening or not happening and make appropriate adjustments to how they understand, relate and lead in the context of these different cultures. It is noted to be an adaptable state that can be developed over time.

Earley and Ang (2003) define CQ as an individual's capability to adapt effectively to situations of cultural diversity. They proposed CQ as a measure of intelligence which is different from general intelligence (IQ) or emotional intelligence (EI) in that CQ captures a person's capacity to adapt across cultures. On the other hand, Lee and Templer, (2003) contend that individuals who are high in CQ can adapt because they can "deal with many tasks and find new solutions to old problems"(p. 186) [29]. While Imai and Gelfand examined CQ in negotiating skills from 124 American and East Asian negotiators. They concluded that levels of CQ predicted success in negotiating effectively across cultures [30]. A key aspect of cultural adaptation is considered as the ability to use skills that are different from those that individuals use within their own culture [31].

$\mathrm{CQ}$ is a multi-dimensional concept comprising Metacognitive, cognitive, motivational and behavioral dimensions. The meta-cognitive cultural intelligence (CQ- strategy) refers to mental processes that individuals use to acquire and understand cultural knowledge, including knowledge of and control over individual thought processes relating to culture [32]. It involves planning strategy before cross-cultural interactions, adjusting cultural knowledge when interacting with people with different cultural backgrounds and monitoring the accuracy of cultural knowledge during cross-cultural encounters. This dimension is expected to be common in this study where workers are supposed to work in a team but do not necessarily share the same culture for example. On the other hand, Metacognitive CQ actually refers to an individual's conscious cultural awareness that is applied when interacting in a cross cultural situation. This is necessary especially with project leaders in controlling team dynamics.

While cognitive CQ reflects an individual's knowledge of different cultures that has been acquired from either educational or personal experiences. The cognitive component (CQ-knowledge) relates to how an individual makes sense of similarities and difference between cultures. It includes knowledge about the legal and economic systems, religious beliefs, the marriage systems, the art and crafts, language of other cultures, an interpersonal system of different cultures and subcultures [33] and knowledge of the basic framework of cultural values [34].

On the other hand, motivational $\mathrm{CQ}$ refers to the capability to direct resources toward learning about cultural differences. The motivational component, reflects one's propensity to adapt new behaviors when thrust into a culturally unfamiliar setting [35]. It involves the personal inborn preference for interacting with people from different cultures even when working with people whom you share the same culture, still there is confidence on culturally diverse interactions and the management of stress from adjusting to unfamiliar settings. Those managers with high-motivational CQ direct attention and energy toward cross-cultural situations based on the intrinsic interest [36].

Finally, behavioral $\mathrm{CQ}$ is the ability to exhibit the appropriate verbal and non-verbal actions when interacting with people from different cultures [37]. People from different cultural backgrounds interpret non-verbal cues differently for example. This definition was used because it appears to be the only CQ definition so far to have been operational zed into a self-report measure. Additionally, it is also the most studied definition of CQ, most likely due to the existence of the self report measure.

CQ is a dynamic competency which could be acquired through training unlike stable competencies such as personality traits which are less related to training. It represents an individual's competence to successfully adapt to new and unfamiliar surroundings and still be equally productive at work.

Although it has become an international assignment requirement for expatriate managers with higher levels of CQ to work within a range of different cultural backgrounds according to [38], there is need to find the influence of higher levels of CQ on project team dynamics as individuals from different cultural background interact. It has been 
suggested that the socialization experience of individual expatriates and the locals should result in a more control of a new cultural environment and may be partially related to cultural adjustment and performance during expatriation [39].

According to social learning theory, the degree of individual interaction with other groups of people through learning about different cultural backgrounds [40] will be related to work performance and consequently project outcome [41].

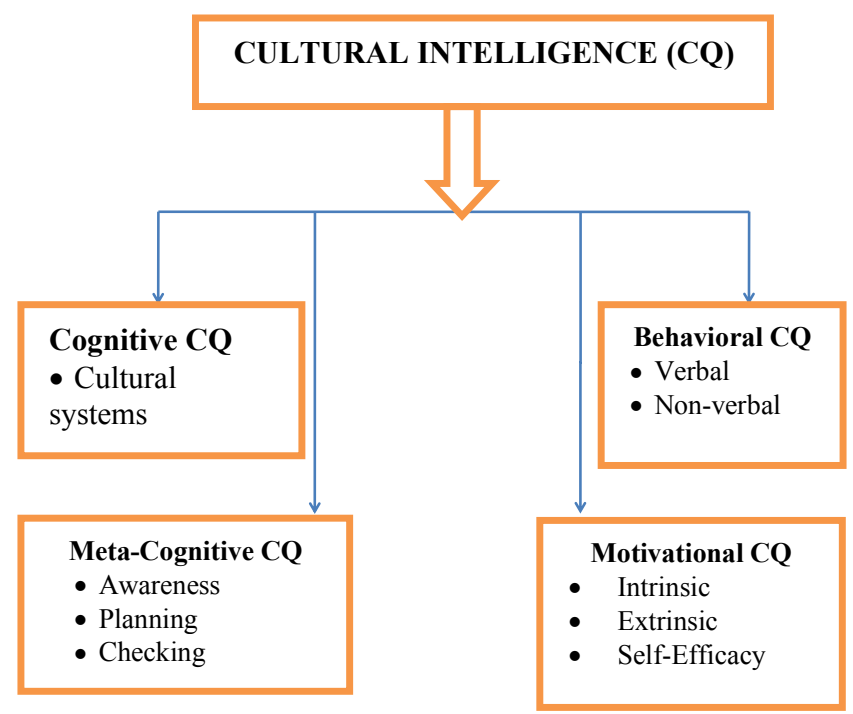

Fig. 1. Four factor model of Cultural Intelligence (CQ)

The above is the CQ model to be adopted in this study. When expatriates have higher levels of capability to adapt across cultures, they tend to have higher performance[42].

Expatriates with high CQ are more likely than those with low CQ to know which of their decisions can be made and accepted by host national cultures [43]. Expatriates with high CQ who have higher levels of adaption regarding their leadership styles (i.e. transformational leadership) will be better able to achieve higher levels of adjustment and performance in a host national culture, for example Kenyan culture for the sake of this study. Ang and Van Dyne study argues that expatriates having a high level of CQ and posses higher levels of transformational leadership are better able to effectively interact with people from different cultural backgrounds (which in turn is critical to project team dynamic), hence direct the project team towards achieving the project goals[44].

Like culture itself, however, CQ is not inborn. Rather, CQ is an ability constituted by cognitive, motivational, and behavioral components of effective intercultural adaptation which operates together, and which can be developed [45].

Peterson discussed CQ in terms of the abilities or skills of cultural adaptation[46]. He defined CQ as the ability to engage in a set of behaviors that uses skills such as language, interpersonal skills and qualities (e.g. tolerance for ambiguity, flexibility) that are tuned appropriately to the culture-based values and attitudes of the people with whom one interacts. The basic CQ hypothesis states that CQ is a person's ability to function effectively across cultural settings and individuals with high CQ would more effectively adapt to a different culture than people with low CQ. This, in turn, would lead them to perform better during an overseas assignment [47-50].

A number of fairly recent research studies have provided support for this hypothesis. Lee and Sukoco and Kim found evidence showing CQ (as a single factor instead of four separate factors) was positively related to job performance data[51-52]. However it is noted that CQ is related to other types of intelligences. Early and Mosakowski for example noted that cultural intelligence is closely linked with emotional intelligence, but it picks up where emotional intelligence leaves off. Like these other forms of intelligence, CQ complements IQ (cognitive intelligence) by focusing on specific capabilities that are important for effectiveness in cross-cultural situations [53].

Similarly, Chen found all the four facets of CQ predicting performance [54].

Additionally, Ang found evidence that motivational CQ and behavioral CQ predicted performance on a cross-cultural simulation and general work and interaction adjustment. Expatriates with higher levels of CQ are reported to be more likely to adjust faster [55-56].

A question has been raised several times about whether cultural intelligence can be improved through training. However, Chua and Tan acknowledge that while CQ may be partially determined by basic intellectual ability an individual person has, CQ can still be improved through training [57].

\section{B. Team Dynamics}

Team dynamics has been defined as the unseen but felt force that impacts a team. The behavioral relationships between members of a group that are assigned connected tasks within a company. Team dynamics are affected by roles and responsibilities and have a direct impact on productivity. When team dynamics is well established, teams are remarkably open-minded, ready for change and can work in harmony.

Good team dynamics allows team members to let their ideas clash rather than people, what matters here is that the right idea wins, regardless of whose idea it is. Sometime managers should exercise transformational leadership style and be flexible to accept ideas even from junior workers for the sake of unity in the team .Henry Ford once said that coming together is a beginning; keeping together is progress; working together is success [58].

As organizations rely on teams and projects to perform tasks and solve business problems, knowledge integration in teams becomes important [59]. French and Bell defined a team as a group of people or workers who have complementary skills, a higher commitment to common goals, and a higher degree of interdependency and interaction[60]. A team should not be confused with a group; a team is an effective and directed group. All teams are groups but not all groups are teams. A project team may be 
defined as a number of people working closely together to achieve shared common goals. For a team to be effective it must be cohesive, co-operative, directed and motivated .According to Belbin's nine team roles, an appropriate project team consist of nine effective team roles including; team shaper, coordinator, implementer, resource investigator, specialist, evaluator, planter, team worker and a completer/finisher.

Mullins observe that, an effective team leader needs to acquire skills such as sharing information, trusting others and developing an atmosphere of trust, being patient, knowing when to intervene and how best to empower team members towards achieving project goals [61].

On the other hand, Burke and Barron recognized that project teams offer organizations an efficient and effective way of managing multidisciplinary projects in any competitive environment. Burke and Barron observe that, through team dynamics, the team strives to enhance its creativity, innovation, problem solving, decision making, synergy, morale, and work performance. Teams are not normally formed but build with time and although there is no one individual who is perfect, a team can be [62].

Richards argue that team dynamics examines how team members interact and attempt to optimize the interactions to meet the project objectives .When team dynamics works, communication is effective, conflicts are minimized, and the potential for successful project outcomes increases. However, Cleland introduced his research in team dynamics and design, focusing on using teams to implement organizational strategies, particularly the importance of team dynamics to project success. Teams can take on much more risk than individuals can, and teams attempt a high level of greatness that is beyond the realistic hope of any individual [63].

A project team may be defined as a number of people working closely together to achieve shared common objectives. Burke and Barron explain that, through team dynamics, the team strives to enhance its creativity, innovation, problem solving, decision making, synergy, morale and work performance.

However, Verma notes that the effectiveness of a project team depends upon the team's ability to maintain the commitment of its members, especially as the team progresses through stages of development. At every stage the members become more committed and finally own the project.

Rahim stressed the importance of team dynamics and emphasized that the greater the number of individuals in the team, the greater the probability of conflicts and misunderstanding. However, some studies suggest that the best size for a fully participative and effective group that can make decisions quickly and effectively is between 10 to 12 members. On his part, Tuckman indicated that project leadership team building, conflict resolution, and stress management affect team dynamics and performance [64].

Leaders and managers need to focus on internal team dynamics and continue to use other core skills for project success. Some of the most important issues for team leaders are that they have the right mix of people, that they set clear targets and goals, and that the team finds ways to work together productively and generatively.

Nickson and Siddons explained that knowing team dynamics is essential if a person is going to be an effective team member, leader or manager. It is important to understand what happens when people join or leave a team and the effect these changes will have on project outcomes and performance [65].

According to Nickson and Siddons basic team dynamics consist of a team; the people one works with in a project make up the project team. Factors that must be considered in such project teams include team size, members' maturity, complementary skill set, members personalities, each member role within the team,

Team leader's leadership style, the experience of team members, expectations, motivation and reward. Secondly goals, this term includes the team's objectives, the definition of these objectives, time schedule, and the ways in which each team member will contribute to achieving the project goals.

Method/ Path-This term refers to the ways used to achieve the goal, each person's responsibilities, the use of internal and external resources, the team's motivation process, and the reporting and delegation processes.

Also environment-The environment is the area in which the project team operates for example, a department or division of a company and the politics, standards, shared resources, and attitudes of people outside the project team to the project. It also includes the effect of project goals to the surrounding.

Finally External groups-External groups are those that may affect the team, those that have goals that conflict with those of the project team, those that have staff seconded to the team, and those that compete for the same resources. In other words there is conflict of interest.

Although studies show that teams are dynamic entities embedded in a multi-level system along with individual, team and organization, team creativity in a critical problemsolving for the project team would depend on how team members interact with each other during team processes. For example, the understanding of team members' behaviors' would affect the efficiency of problem-solving [66].

Topping declared that an important fact in team dynamics is the application of equity theory. Topping argues that team members do not evaluate equitable treatment in a vacuum. They measure how they are being treated in comparison with how their peers are being treated. Therefore, to maximize team dynamics, leaders must be mindful of the perceived fairness of how they treat individual employees within the team. If one team member perceives that more attention and recognition is being given to another team member whose performance and effort one perceives as no better than his/her own, then one will be dissatisfied with this inequity [67]. 
In general, teams composed of members with different expertise, skills and abilities [team creativity] are considered more creative and innovative than those whose members are similar by sharing different perspectives and expertise [68].

As knowledge and skill diversity is needed for creativity and innovation, it is also important to analyze the way to integrate and facilitate diversity within a team [69]. Members in multinational teams (MNTs) are likely to increase creativity and innovation if they would embrace crossnational divergence, such as ideas from members who have different national backgrounds.

\section{THEORETICAL DEVELOPMENT}

Today's business world is characterized by frequent Crossing of the national boundaries and interactions of people from different cultures, and thus has become multicultural. It is also true that diversity in organizations has resulted in individuals working and interacting regularly with people from different cultural and ethnic background. Cultural differences especially within the context of a project team can make the interactions difficult and resulting in misunderstanding, conflict and disintegration of such teams. It has been emphasized that, for better interaction and management in cross-cultural teams, managers and individuals need to be sensitive to different cultures along with understanding, learning, and adapting new cultures.

CQ is analyzed in terms of the known multi-dimensional concept comprising of Metacognitive, cognitive, motivational and behavioral dimensions. Indicators of a project manager with Metacognitive, are One-Strategy; being conscious of the cultural knowledge when interacting with people of different cultural background. While cognitive CQ indicator include a manager with a general knowledge on the host culture for example cultural values, religious beliefs, marriage systems, local language, rules for expressing nonverbal cues etc. Thirdly, motivational $\mathrm{CQ}$ involve the expatriate or local managers' level of motivation and finally the behavior pattern including verbal and no-verbal behaviors.

While project team dynamics is observed in terms of both internal and external team dynamics. Internal dynamics have to do with what makes a particular team successful in terms of its own operating rules and how the team members interact with each other. External dynamics have to do with how an organization creates and nurtures the teams. Indicators of team dynamics shall include but not limited to team members communication, members view of other team members, cultural differences, Level of Morale/motivation as a member of the project team, level of trust and working together in unity, job security, commitment and so on.

Sahin also conducted a research and found that high levels of leader motivational and behavioral CQ are related to subordinate ratings of satisfaction with leader and organizational citizenship behaviors [70]. Based on their research, Amiri found a significant relationship between Metacognitive, cognitive and motivational aspects of CQ and employees' performance or between CQ and employees' performance overall [71].
The element of trust in a team is very vital, a team member should care and show concern for each other and to have faith in each other's honesty and commitment. The project team leaders identity and helps team members to make the group's goals their own; this makes all members to focus on one thing. Group efficacy is also key where team members need to be confident with working together in accomplishing organizational task.

Previous research showed that CQ has implications over the project managers' decision making, cultural adaptability, cultural adjustment and performance; similarly, project managers' CQ might affect the ability to influence team dynamics for managers who are involved in cross-cultural business or work interactions.

Before you begin to format your paper, first write and save the content as a separate text file. Keep your text and graphic files separate until after the text has been formatted and styled. Do not use hard tabs, and limit use of hard returns to only one return at the end of a paragraph. Do not add any kind of pagination anywhere in the paper. Do not number text heads-the template will do that for you.

\section{A. Research prepositions}

This article proposes that as far as the four dimensions of CQ: Metacognitive, cognitive, motivational and behavioral as described by Ang, are concerned each dimension has a relationship with team dynamics. This lead to the following propositions

\section{B. Research Proposition}

Metacognitive CQ is positively related to team dynamics. Metacognitive CQ involves planning, self-monitoring, and use of cognitive strategies [72]. Managers with high level of Metacognitive skills are able to understand, interpret and act according to these cues. However such skills influence team dynamics as the project managers interact with their teams. Meta-cognitive CQ is also viewed as a high order mental capability that a manager or a leader posses to think about personal thought processes, to anticipate the cultural preferences of others and to adjust mental models during intercultural experiences. It includes awareness of the cultural setting planning and checking.

For instance, awareness of the host country culture gives an insight into one's culture as behaviors accepted in one culture may not be accepted elsewhere. This is key for crosscultural team dynamics where Chinese and Kenyans workers are expected to interact freely in such projects. Van Dyne describe meta-cognitive $\mathrm{CQ}$ as a link between understanding the cultural issues and applying them during cross-cultural encounters. This is fundamental for project managers who are faced daily with issues such as conflict resolution in the cross cultural teams without showing any partiality.

On such international projects or assignments, an important pre-requisite for adjustment and positively influencing team dynamics would be an individual's ability to gauge differences between home and host country cultures and then deal with team members appropriately. Therefore, 
along with cognitive skills, cultural adjustment also requires a set of highly complex meta-cognitive skills. Since metacognitive CQ helps an individual based upon his/her cultural understanding, to plan and interpret diverse cultural contexts. This may have implications on project team depending on how the manager handles the team.

Project managers' cognitive cultural intelligence has a significance relationship with project team dynamics. Although Cognitive CQ is conceptualized, through selfconcept theory, which refers to the information processing aspect of intelligence. It involves individual's interest and knowledge of norms, practices and conventions in different cultures which could be acquired with time through experience and formal education. Project managers' Cognitive CQ is a necessary pre-requisite in management of cross-cultural teams, as it helps the manager to properly handle the social situation based on basic cultural knowledge and to function efficiently within that environment.

Since an individual is able to simultaneously use and adjust his knowledge about a foreign culture, indicates that he/she is able to let go those personal beliefs which conflict with the host culture [73]. As a result, it is observed that Cognitive CQ has a positive effect on general interaction with team, work adjustment and team dynamics.

\section{Research Proposition}

Motivational CQ will positively predict team dynamics. Motivational CQ has been defined as an individual's capability to direct his/her attention and energy towards learning about and functioning in intercultural situations. Managers with a higher Motivational CQ normally enjoy cultural interactions when working in cross-cultural teams and shows confidence in being effective in such cultural encounters.

Templer suggest that individuals with a high motivational CQ also are not only confident with their ability to adapt to new environments but they are also intrinsically interested in and motivated to explore and experience diverse cultures. Furthermore the self-efficacy component of motivational CQ helps an individual to be persistent in stressful work situations when dealing with people from different cultural background yet they are members of the project teams, as characterized by most construction projects and successfully navigate through it [74]. Therefore, motivational CQ is positively related to influence on project team dynamics.

\section{Equations}

A higher behavioral CQ of the project manager enhances effective communication within the project team, leading to a positive influence on team dynamics.

Behavioral $\mathrm{CQ}$ is the product of the cognitive and motivational facets of CQ. It depict the ability of the manager to use behavior that is acceptable to people from other cultures. Triandis contends that appropriate behaviors vary with different cultures in question.

Problems in communication can still occur due to different accents and tones potentially causing misinterpretations, therefore a certain amount of behavioral awareness is necessary to be effective when involved in cross-cultural communications.

Since cultural interactions in a cross-cultural team require individuals to portray the right behaviors, therefore the behavioral component of CQ plays an essential role as it addresses verbal and non-verbal aspects of social interactions. Individuals, project managers and leaders high on this component are competent enough to deal with a wide range of team members behaviors and they are able to exhibit verbal and non-verbal cues appropriate as the situation demands [75]. As a result of these, Behavioral CQ has a positive and significant influence on interaction adjustment.

\section{The Implications Of CQ For Project Managers}

Cultural intelligence enables managers and other team players to understand and perform better the role or task assigned to them as a part of their official job responsibilities. It is important for workers to have not only the knowledge about the cultures they have to deal with but also the ability to handle it positively and efficiently. It has been noted that the organizational performance depends on the manager's ability to handle tactfully cultural difference among the workers [76].

It has been observed that culturally intelligent managers are better able to interact with workers of different cultural background, which help them to perform their job effectively. They are flexible and they can handle effectively the cultural shocks and stresses. Stress experienced due to manager's or a member of the project team inability to adjust to new cultural environment may cause cognitive fatigue and take away the energy and confidence required for successful implementation of work, hence performance is effected [77].

Cultural intelligence helps managers to adjust themselves with culturally different Situations; managers or leaders who have the ability to cope with various types of stress associated with cross-cultural interaction are better able to adjust in a new cultural environment.

Ramalu also asserts that individuals with a high cultural intelligence are expected to adjust better in a new cultural environment, which in turn enhances performance. The workers who are culturally intelligent are better able to adjust themselves with the local food, cost of living, shopping and entertainment facilities of any cultural different environment he/she is working in, this help them to enhance their performance. Further, they can communicate as well adapt to a new cultural context easily and effectively[78].

Cultural intelligence serves as an important selection tool. People with high cultural intelligence are able to give their best performance and these people can be sent for international assignments as they are able to interact effectively with people outside their culture. Organizations should pay more attention to CQ during the staff selection process, since higher CQ, implies a better level of adjustment. In case organizations select someone with extensive international experience but a low level of $\mathrm{CQ}$, such persons 
might face more difficulties in adjusting themselves to the new environment.

Managers with greater Metacognitive skills should be able to understand, interpret and act according to the required cognitive strategies. While managers with high levels of behavioral CQ are likely to be capable of exerting situational appropriate behaviors based on their broad range of verbal and nonverbal capabilities, such as presenting culturally appropriate words, tone, gestures, facial expressions and body language.

\section{FUTURE RESEARCH DIRECTIONS}

It is worth noting that most theories and models existing in literature focus on the impact of cultural intelligence on expatriates adjustment but there is limited research done on the influence of cultural intelligence among supervisors or managers on project team dynamics.

Although a study conducted by Earley and Gardner examines the relationship between internal team dynamic and cultural Intelligence among some multinational teams, the element of external team dynamics was overlooked in this study. Therefore the need to explore further the influence of all the four facets of CQ on both internal and external team dynamics. External team dynamics is key and involves how the organization builds project teams and maintains them to realize positive project outcomes.

There is need to further explore the scope of CQ and its influence on team dynamics especially based on this case study, for the Kenya native companies have faced among other challenges the problem of managing team dynamics within the project teams for many years.

A number of empirical studies done in the literature indicates that CQ has implications for cultural judgment, decision making, project managers' need for achievement, and workers performance.

Overall, CQ allows an individual to appreciate the diversity of experiences to formulate rapid, accurate and situationally sensitive responses to emerging issues especially at work. Also Lu, noted that a high level of CQ enhances adjustment by reducing stress ,appreciating diversity within a team which in turn mediates the relationship between $\mathrm{CQ}$, expatriate performance and completion of the given assignment [79].

In this regard, several potential research areas are available and need to be further investigated. Studying the impact of project managers CQ on the project team, goals, path or the method of achieving the project objectives, project environment and the external groups that may affect the performance of a project in one way or another. Such research direction will be a great contribution to the existing literature and the general body of knowledge.

\section{SUMMARY}

The findings of a study with this research direction have potential implications for expatriate and professional within cross-cultural team management. A study by Price Water
House Coopers suggests that although Engineering and Construction firms recognize the importance of international mobility and talent management, very few have developed a systematic approach to link the two. Given the profound skills shortages across the construction industry, recruiting, rewarding and retaining top talent including a high CQ profile to manage team dynamics becomes vital [80].

A clear understanding towards the potential effects of overall CQ on team dynamics is critical to realize better project performance while dealing with cross cultural teams both internationally or in the host country. The proposed frame work in this article can be resourceful in guiding and designing more focused cross-cultural training programs especially for project managers who are expected to deal with cross cultural teams.

\section{ACKNOWLEDGEMENTS}

I do acknowledge my supervisor Dr. Ying Zhang for her guidance and giving me insight in my Research work.

\section{REFERENCES}

[1] L. Kyle, "Language, cultural intelligence and expatriate success," Management Research Review, vol. 36, 2013, pp. 596 - 612.

[2] M. Zeidner, G. Matthews, and R.D. Roberts, "Emotional intelligence in the workplace: a critical review," Applied Psychology: An International Review, vol. 53, 2004, pp. 371-99.

[3] J. Selmer, "The preference for pre-departure or post-arrival crosscultural training - an exploratory approach", Journal of Managerial Psychology, vol. 16, 2001, pp. 50-8.

[4] A. Wellner, "How do you spell diversity?" Training, vol. 37, 2000, pp. 34-38.

[5] J. Jeevan, "Assessing the cultural intelligence and task performance equation," Cross Cultural Management, 2015, vol. 22, pp. $236-$ 258.

[6] A. Furnham, "Communicating in foreign lands: the cause, consequences and cures of culture shock," Language, Culture and Curriculum, vol. 6, 1993, pp. 91-109.

[7] A.S.Y. Chen, Y.C. Lin, and A. Sawangpattanakul, "The relationship between cultural intelligence and performance with the mediating effect of cultural shock: a case from Philippine labourers in Taiwan," International Journal of Intercultural Relations, vol. 35, 2011, pp. 246-258.

[8] G. Chen, B.L. Kirkman, K. Kim, C.I. Farh, and S. Tangirala, "When does cross-cultural motivation enhance expatriate effectiveness? A multilevel investigation of the moderating roles of subsidiary support and cultural distance," Academy of Management Journal, vol. 53, 2010, pp. 1110-1130.

[9] R.P. Bagozzi, Y. Yi, and L.W. Phillips, "Assessing construct validity in organizational research,"Administrative Science Quarterly, vol. 36, 1991, pp. 421-458.

[10] L.Y. Lee, and B.M. Sukoco, "The effects of cultural intelligence on expatriate performance: the moderating effects of international experience," The International Journal of Human Resource Management, vol. 21, 2010, pp. 963-981.

[11] "Ministry of finance Kenya- China sign standard gauge railway agreement," 2014.

[12] Ministry of Transport and Infrastructural development Uchukuzi'Standard Gauge Railway Forging New frontier in Railway Development In Kenya and the Region'. A magazine of the Ministry of Transport and Infrastructural development, June 2014. 
[13] K.Y. Ng, and P.C. Earley, "Culture and intelligence: old constructs, new frontiers", Group Organization Management, vol. 31, 2006, pp. 4-19.

[14] J. Jeevan, "Assessing the cultural intelligence and task performance equation," Cross Cultural Management, vol. 22, 2015, pp. $236-258$.

[15] K.Y. Ng, and P.C. Earley, "Culture and intelligence: old constructs, new frontiers," Group Organization Management, vol. 31, 2006, pp. 4-19.

[16] S. Ang, "Cultural intelligence: Its measurement and effects on cultural judgment and decision making, cultural adaptation and task performance," Management and Organization Review, vol. 3, 2007, pp. 335-371.

[17] P.C. Earley, and S. Ang, "Cultural Intelligence: Individuals Interactions Across Cultures," Stanford University Press, Palo Alto, 2003

[18] P.C. Earley, and E. Mosakowski, "Cultural intelligence", Harvard Business Review, vol. 82, 2004, pp. 139-146.

[19] M.T. Charles, and Green, "A Study of The Interrelationship of Interpersonal Skills, Team Dynamics, and Emotional Intelligence and its effects on Project outcomes within the Integrated Materiel Management Center: A Case Study," Capella University, March 2010.

[20] H. Gardner, "Intelligence Reframed: Multiple Intelligence for the 21st Century," Barrie Books, New York, 2005.

[21] H. Kinuthia, "History of the Kenya Railway," Destination Magazine, 2014, pp. 2-4.

[22] B. Young, "Managing projects in China - what could possibly go wrong?" 2013.

[23] L.Y. Lee, and B.M. Sukoco, "The effects of cultural intelligence on expatriate performance: the moderating effects of international experience," International Journal of Human Resource Management, vol. 21, 2010, pp. 963-981.

[24] G. Hofstede, “Culture's consequence,” Newbury Park, CA: Sage Publications, 1984.

[25] G. Hofstede, "Cultures and organizations: Software of the mind," New York: McGraw-Hill Book Company, 1991.

[26] P.G. Northouse, "Improving expatriate adjustment and effectiveness in ethnically diverse countries: marketing insights," Cross Cultural Management: An International Journal, vol. 13, 2007, pp. 156-170.

[27] D.C. Thomas, E. Elron, G. Stahl, B.Z. Ekelund, E.C. Ravlin, J.L. Cerdin, S. Poelmans, R. Brislin, A. Pekerti, Z. Aycan, M. Maznevski, A. Kevin, and M.B. Lazarova, "Cultural intelligence: domain and assessment," International Journal of cross Cultural Management, vol. 8, 2008, pp. 123-143.

[28] P.C. Earley, and S. Ang, "Cultural Intelligence: Individuals Interactions Across Cultures," Stanford University Press, Palo Alto, CA, 2003.

[29] L. Lee, and B.M. Sukoco, "The effects of cultural intelligence on expatriate performance: the moderating effects of international experience," International Journal of Human Resource Management, vol. 21, 2010, pp. 963-981.

[30] A.M. Ismail, R. Reza, and S. Mahdi, "Analysis the relationship between cultural intelligence and transformational leadership," International Journal of Business and Social Science, 2012, vol. 3, pp. 252-261

[31] P.C. Earley, and S. Ang, "Cultural Intelligence: Individuals Interactions Across Cultures," Stanford University Press, Palo Alto, CA. 2003.

[32] J.H. Flavell, "Meta-cognitive and cognitive monitoring: a new area of cognitive inquiry," American Psychologist, vol. 34, 1979, pp. 906-911.

[33] P.C. Earley, and R.S. Peterson, "The elusive cultural chameleon: cultural intelligence as a new approach to intercultural training for the global manager," Academy of Management Learning and Education, 2004, vol. 3, 2004, pp. 100-115
[34] G. Hofstede, "Culture's Consequences (Second Edition): Comparing Values, Behaviors," Institutions and Organizations Across Nations, Sage Publications, Thousand Oaks, 2001.

[35] P.C. Earley, and R.S. Peterson, "The elusive cultural chameleon: cultural intelligence as a new approach to intercultural training for the global manager," Academy of Management Learning and Education, vol. 3, 2004, pp. 100-115.

[36] E.L. Deci, and R.M. Ryan, "Intrinsic Motivation and SelfDetermination in Human Behavior," Plenum, New York, 1985.

[37] S. Ang, L. Van Dyne, and C. Koh, "Personality correlates of the four-factor model of cultural intelligence," Group and Organization Management, vol. 31, 2006, pp. 100-123.

[38] M.A. Shaffer, D.A. Harrison, and K.M. Gilley, "Dimensions, determinants, and differences in the expatriate adjustment process," Journal of International Business Studies, vol. 30, 1999, pp. 557-81.

[39] J.S. Black, and H.B. Gregersen, "Antecedents to cross-cultural adjustment for expatriates in Pacific rim assignments," Human Relations, vol. 44, 1991, pp. 497-515.

[40] K.J. Templer, C. Tay, and N.A. Chandrasekar, "Motivational cultural intelligence, realistic job previews and realistic living conditions preview and cross-cultural adjustment," Group Organization Management, vol. 31, 2006, pp. 154-173.

[41] S. Jun, S. Lee, and J.W. Gentry, "The effects of acculturation on commitment to the parent company and the foreign operation," International Business Review, vol. 6, 1997, pp. 519-35.

[42] L.V. Dyne, and S. Ang, "Cultural Intelligence: An Essential Capability for Individuals In Contemporary Organizations,” Global EDGE, 2005.

[43] R.J. Sternberg, and D.K. Detterman, "What is Intelligence?" Ablex, Norwood, 1986.

[44] C. Koh, D. Joseph, and S. Ang, "Cultural Intelligence and collaborative work: intercultural competencies in global technology work teams,"presented at International Workshop onn Intercultural Collaboration, Palo Alto, pp. 20-21, February 2009.

[45] L.V. Dyne, and S. Ang, "Cultural Intelligence: An Essential Capability for Individuals In Contemporary Organizations,” Global EDGE, 2005.

[46] K. Kim, "Individual differences and expatriate assignment effectiveness: The case of US-based Korean expatriates," Journal of World Business, vol. 43, 2008, pp. 109-126.

[47] P.C. Earley, and S. Ang, "Cultural Intelligence: Individuals Interactions Across Cultures," Stanford University Press, Palo Alto, 2003.

[48] L.Y. Lee, and B.M. Sukoco, "The effects of cultural intelligence on expatriate performance: the moderating effects of international experience," The International Journal of Human Resource Management, 2010, vol. 21, pp. 963-981.

[49] K. Kim, and J.W. Slocum, "Individual differences and expatriate assignment effectiveness: the case of US-based Korean expatriates," Journal of World Business, vol. 43, 2008, pp. 109-126.

[50] K. Kim, "Individual differences and expatriate assignment effectiveness: The case of US-based Korean expatriates," Journal of World Business, vol. 43, 2008, pp. 109-126.

[51] L.V. Dyne, and S. Ang, "Cultural Intelligence: An Essential Capability for Individuals In Contemporary Organizations,” Global EDGE, 2005

[52] C.Y. Qin, "The impact of cross-cultural training for expatriates in a Chinese firm," Career Development International, vol. 15, 2010, pp. 296 - 318.

[53] P.C. Earley, and E. Mosakowski, "Cultural intelligence," Harvard Business Review, 2004, vol. 82, 2004, pp. 139-146.

[54] P.C. Earley, and R.S. Peterson, "The elusive cultural chameleon: cultural intelligence as a new approach to intercultural training for the global manager," Academy of Management Learning and Education, vol. 3, 2004, pp. 100-115.

[55] M.A. Shaffer, D.A. Harrison, H. Gregersen, J.S. Black, and L.A. Ferzandi, "You can take it with you: individual differences and 
expatriate effectiveness," Journal of Applied Psychology, vol. 9, 2006, pp. 109-125.

[56] K.J. Templer, C. Tay, and N.A. Chandrasekar, "Motivational cultural intelligence, realistic job preview, realistic living conditions preview, and cross-cultural adjustment," Group \& Organization Management, vol. 31, 2006, pp. 154-173.

[57] B. Young, "Managing projects in China - what could possibly go wrong? Article 4 - Dragons, Camels \& Kangaroos," PM World Journal, 2013, vol. 2.

[58] E.G. Ochieng, and A.D.F. Price, "Managing cross-cultural communication in multicultural construction project teams," International Journal of Project Management, vol. 28, 2010, pp. 449-460.

[59] R.B. Peterson, N.K. Napier, and W. Shul-Shim, "Expatriate management: comparison of MNCs across four parent countries," Thunderbird International Business Review, vol. 42, 2015, pp. 145166.

[60] J. Jeevan, "Assessing the cultural intelligence and task performance equation," Cross Cultural Management, vol. 22, 2015, pp. 236 - 258.

[61] J. Creswell, "Research Design. Qualitative, Quantitative and Mixed Methods Approaches.3rd Edition," SAGE publications Ltd, 55 city Road, London ECIY ISP- United Kingdom, 2009.

[62] N Nicholson, "A theory of work role transitions," Administrative Science Quarterly, vol. 29, 2006, pp. 172-191.

[63] J.C. Nunnally, "Psychometric Methods," McGraw Hill, New York, 1997.

[64] M. Saunders, P. Lewis, and A. Thornhill, "Research Methods for Business Students," Prentice Hall, London 2007.

[65] J. Selmer, "Cross-cultural training and expatriate adjustment in China: western joint venture managers," Personnel Review, vol. 34, 2005, pp. 68-84.

[66] Y. Zhang, "Expatriate development for cross-cultural adjustment: Effects of cultural distance and cultural intelligence," Human Resource Development Review, vol. 12, 2013, pp. 176-198.

[67] Y. Zhang, "Two-way Flow Expatriation between China and Australia," Beijing: Economic science Press, 2015.
[69] K. Karma, and R. Vedina, "Cultural intelligence as a prism between workforce diversity and performance in a modern organisation,' Review of International Comparative Management, vol. 10, 2009, pp. 527-542.

[70] M.L. Kraimer, S.J. Wayne, and R.A. Jaworski, "Sources o support and expatriate performance: the mediating role of expatriate adjustment," Perspective Psychology, vol. 54, 2001, pp. 71-99.

[71] S. Ramalu, R.C. Rose, N. Kumar, and J. Uli, "Cultural intelligence and expatriate performance in global assignment: the mediating role of adjustment," International Journal of Business and Society, vol. 13, 2012, pp. 19-32.

[72] A.W. Andreason, "Direct and indirect forms of in-country support for expatriates and their families as a means of reducing premature returns and improving job performance," International Journal of Management, 2003, vol. 20, pp. 548-52.

[73] Y. Zhang, and Oczkowski, Edward, "Exploring the potential effects of expatriate adjustment direction," Cross Cultural \& Strategic Management, vol. 23, 2016, pp. 158- 183.

[74] Price Water Coopers International Mobility in the Engineering \& Construction Industry Analysis and Insight on Trends and Best Practice, Price Water Coopers, 2008.

[75] B.L. Kirkman, G. Chen, J.L. Farh, and K.B. Lowe, "Individual power distance orientation and follower reactions to transformational leaders: a cross-level, cross-cultural examination," Academy of Management Journal, vol. 52, 2009, pp. 744-764.

[76] G. Hofstede, and G.J. Hofstede, "Cultures and Organizations: Software of the Mind," McGraw-Hill, New York, 2005.

[77] H. Gardner, "Intelligence Reframed: Multiple Intelligence for the 21st Century," Barrie Books, New York, 1999.

[78] S. Ramalu, R.C. Rose, N. Kumar, and J. Uli, "Doing business in global arena: an examination of the relationship between cultural intelligence and cross-cultural adjustment," Asian Academy of Management Journal, vol. 15, 2010, pp. 79-97.

[79] A. Wellner, "How do you spell diversity?" Training, vol. 37, 2000, pp. 34-38.

[80] J.I. Sanchez, P.E. Spector, and C.L. Cooper, "Adapting to a boundary less world: a developmental expatriate model," The Academy of Management Executive, vol. 14, 2000, pp. 96-106.
[68] L. Van Dyne, S. Ang, and D. Livermore, "Cultural intelligence: a pathway for leading in a rapidly globalized world," Leading Across Differences, Pfeiffer, San Francisco, 2010, pp. 131-138. 